Mohammed Abo-Zahhad et al., A new ECG compression algorithm based on wavelet foveation and Huffman coding techniques, pp. 2213 - 2230

\title{
A New ECG Compression Algorithm Based On Wavelet Foveation And Huffman Coding Techniques
}

\author{
Mohammed Abo-Zahhad ", Sabah M. Ahmed and Ahmed Zakaria \\ Electrical and Electronics Department, Faculty of Engineering, Assiut University, Egypt
}

Received 10 May 2013; accepted 14 June 2013

\begin{abstract}
This paper introduces a new ECG signal compression algorithm based on modulating the ECG signal DWT coefficients with a proper mask constructed using the foveation principle. The constructed mask is a selective mask that gives a high resolution at a certain point (fovea) and falls down away from this point. The wavelet foveation of the ECG signal leads to decreasing the amount of information contained in the signal. So, the value of the foveated ECG signal Entropy will be decreased which by turn will increase the Compression Ratio (CR). The ECG signal after wavelet foveation is coded using Huffman codes; namely optimal selective Huffman coding, adaptive Huffman coding and modified adaptive Huffman coding. The performance of each coding technique is measured based on the CR, time cost and computational complexity.
\end{abstract}

Keywords: Wavelet Foveation; Optimal selective Huffman Coding; Adaptive Huffman Coding; Modified Adaptive Huffman Coding and Lossless compression.

\section{Introduction}

ECG signal has an important role in diagnosis of heart diseases. ECG compression has a great importance to reduce storage requirements and/or the transmission rate for ECG data transmission over telephone lines or digital telecommunication networks. The desired objective is to provide a high-quality reconstruction of electrocardiogram signals at low bit rates and acceptable distortion levels. Many algorithms for ECG data compression have been proposed in the last three decades [1] - [18] to achieve high compression ratios and good signal quality without affecting the diagnostic features in the reconstructed signal. The current technologies provide sufficient space to store or transmit data, so now it is no more a big problem. However the continuous effort to reduce the time requirement has made the ECG data compression more focused and thus has received much attention.

Lossless compression schemes [12]-[14], are preferable than lossy compression schemes in biomedical applications where even the slight distortion of the signal may result in erroneous diagnosis. The application of lossless compression for ECG signals is motivated by the following factors;

- A lossy compression scheme is likely to yield a poor reconstruction for a specific portion of the ECG signal, which may be important for a specific diagnostic application. Furthermore, lossy compression methods may not yield diagnostically acceptable results for the records of different arrhythmia conditions. It is also difficult to identify the error range, which can be tolerated for a specific diagnostic application.

\footnotetext{
* Corresponding author.

E-mail address: zahhad@yahoo.com
} 
Mohammed Abo-Zahhad et al., A new ECG compression algorithm based on wavelet foveation and Huffman coding techniques, pp. 2213 - 2230

- In many countries, from the legal point of view, reconstructed biomedical signal after lossy compression cannot be used for diagnosis [15].

Hence, there is a need for effective methods to perform lossless or near lossless compression of ECG signals. The near lossless compression schemes proposed in this paper can be applied to a wide variety of biomedical signals including ECG and they yield good signal quality at reduced compression efficiency compared to the known lossy compression methods. In this paper it is proposed to compress the ECG signal using the wavelet foveation criteria [16]-[17]. The wavelet foveated ECG signal can be obtained by a space variant smoothing process where the width of the smoothing function used is small near the fovea point and gradually expanded as the distance from the fovea point increases. Then the foveated ECG wavelet coefficients are coded using different coding schemes, which all are based on Huffman coding [18]-[19]. The basic idea in Huffman coding is to assign short code-words to those input symbols with high probabilities and long codewords to those with low probabilities [20].

The block diagram of the proposed approach is indicated in Figure (1). It shows that firstly the ECG signal is preprocessed and split into beats segments by detecting the QRScomplex. Based on the characteristics points provided by the first stage a separate module computes the foveation mask, which its parameters are mainly influenced by the width of region-of-interest. Then subsequently the DWT of each separate ECG beat is performed and modulate the resulted coefficients by multiplying those with the corresponding foveation mask. The number of the resulted (masked) DWT coefficients will decrease considerably. Lastly one of the listed coding schemes is used to code these masked DWT coefficients.

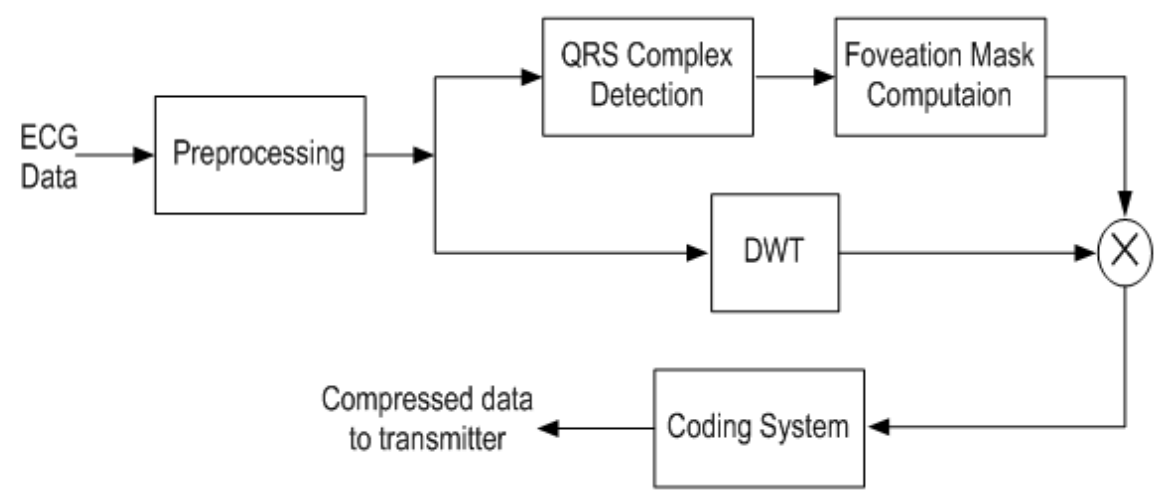

Fig1. The Proposed Compression Algorithm

\section{QRS Detection}

There are many schemes that have been introduced in literature for QRS-complex detection which is the most significant features of the ECG signal. The difference between these schemes is in the used QRS detection method and the ability of the scheme to deal with all ECG signals without any human control. Here, the proposed scheme was tested on records from the MIT-BIH arrhythmia database. Numerical results show that the used

Journal of Engineering Sciences, Assiut University, Faculty of Engineering, Vol. 41, No. 6, November, 2013, E-mail address: jes@aun.edu.eg 
Mohammed Abo-Zahhad et al., A new ECG compression algorithm based on wavelet foveation and Huffman coding techniques, pp. 2213 - 2230

detection process is excellent. Figure (2) illustrates an example of detecting the QRScomplexes of record number 103 extracted from MIT-BIH database.
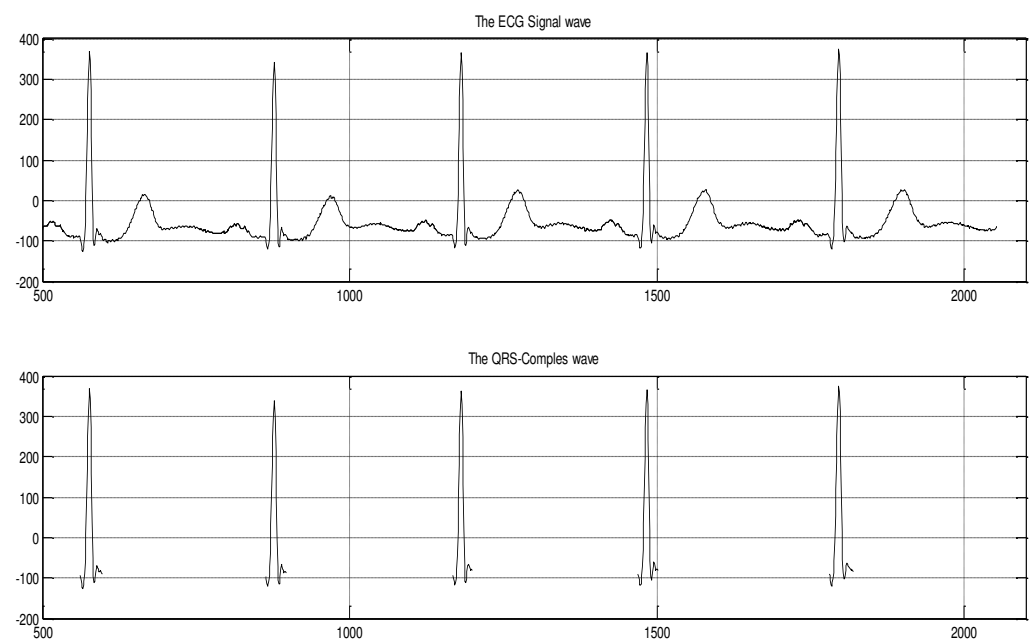

Fig. 2. An example of detecting the QRS-complexes of record number 103 extracted from MIT-BIH database.

\section{Foveation Criteria}

The spatial resolution of the human visual system is highest at the center of the retina (fovea), and decreases rapidly away from it. Formation of signals that resemble this spatially variant property is called foveation. In space-variant foveation systems, the Area Of Interest (AOI) is maintained at high resolution, while areas away from it where precise detail may be less critical, are coded at lower resolution. With this structure, the average resolution is considerably lower than that obtained using standard uniformly sampled highresolution structure. Thus, considerable increase in compression ratio can be achieved. A wavelet foveated ECG signal is obtained from a uniform resolution signal through a spacevariant smoothing process where the width of the smoothing function is small near the fovea but gradually increases towards the peripheral. In one dimension, the foveation of a function $f: R \rightarrow R$ is determined by a smoothing function $g: R \rightarrow R$, and a weighting function $\omega: R \rightarrow R \geq 0$. Foveation of a signal has been modeled as space-variant smoothing as defined in [16] according to:

$$
(T f)(x)=\int_{-\infty}^{\infty} f(t) \frac{1}{\omega(x)} g\left[\frac{t-x}{\omega(x)}\right] d t
$$

where, $f(t)$ is the foveated signal, $\omega(x)=\alpha|x-\gamma|+\beta$ is the weighting function and $\mathrm{g}(\mathrm{x})$ is the smoothing function. Both $\alpha$ and $\beta$ are non-negative parameters. $\alpha$ is called the rate as it determines how fast resolution falls off, $\gamma$ is called the fovea as it determines the point of highest resolution, and $\beta$ is called the foveal resolution as it determines the resolution at the fovea. In this paper $\beta$ is chosen to be unity and $\alpha$ is determined by the width of the QRS

Journal of Engineering Sciences, Assiut University, Faculty of Engineering, Vol. 41, No. 6, November, 2013, E-mail address: jes@aun.edu.eg 
Mohammed Abo-Zahhad et al., A new ECG compression algorithm based on wavelet foveation and Huffman coding techniques, pp. 2213 - 2230

region and $\gamma$ is the position of the R point of the ECG period. The weighting function $\mathrm{g}(\mathrm{x})$ is formulated as

$$
g(x)=a e^{-\frac{(x-b)^{2}}{2 c^{2}}}
$$

where, $a$ is the height of the smoothing curve's peak, $b$ is the position of the center of the peak, and c controls the width of the "bell". The foveation operator can be treated as an integral operator

$$
(T f)(x)=\int_{-\infty}^{\infty} k(x, t) f(t) d t
$$

where, $k(x, t)$ is the kernel of $t$ or the wavelet foveation mask. This mask is a 2D matrix as shown in Figure (3). Figures (4) and (5) show the 1'st, 120'th and 480'th rows of the mask matrix and the contour plot of the mask kernel, where the fovea point at sample 120 of the ECG signal. To have a wavelet foveated ECG signal in time domain a certain ECG beat is multiplied by the accompanied mask as:

$$
Y=k \times S
$$

where $\mathrm{k}$ is the foveation mask and $\mathrm{S}$ is the ECG signal to be foveated. The ECG signal and the resulted foveated ECG signal are shown in Figure (6). We subsequently perform DWT decomposition of the ECG segments and modulate the resulted coefficients by multiplying them by the corresponding mask.

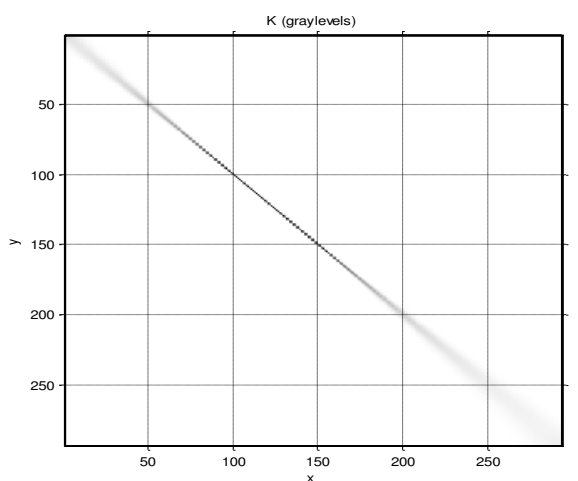

Fig. 3. The mask matrix in time domain

Journal of Engineering Sciences, Assiut University, Faculty of Engineering, Vol. 41, No. 6, November, 2013, E-mail address: jes@aun.edu.eg 
Mohammed Abo-Zahhad et al., A new ECG compression algorithm based on wavelet foveation and Huffman coding techniques, pp. 2213 - 2230
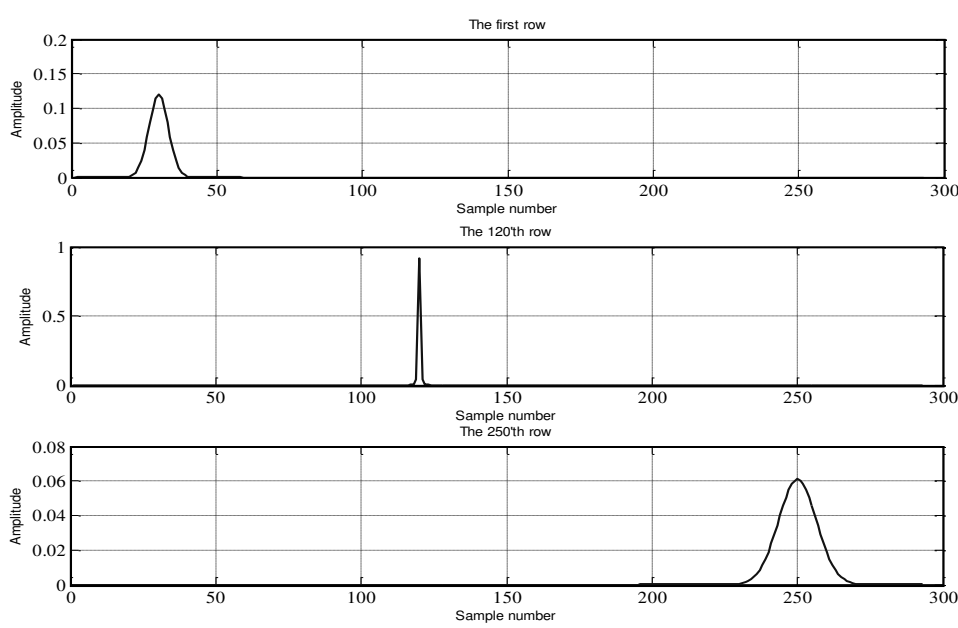

Fig. 4. The 1'st, 120th and 480th rows of the mask matrix.

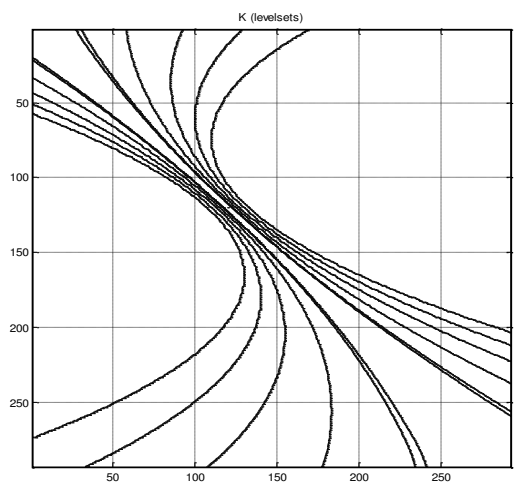

Fig. 5. The kernel plotted as an image (darker pixel corresponds to a larger value) together with its contour plot. Observe that it is smooth except at the origin.
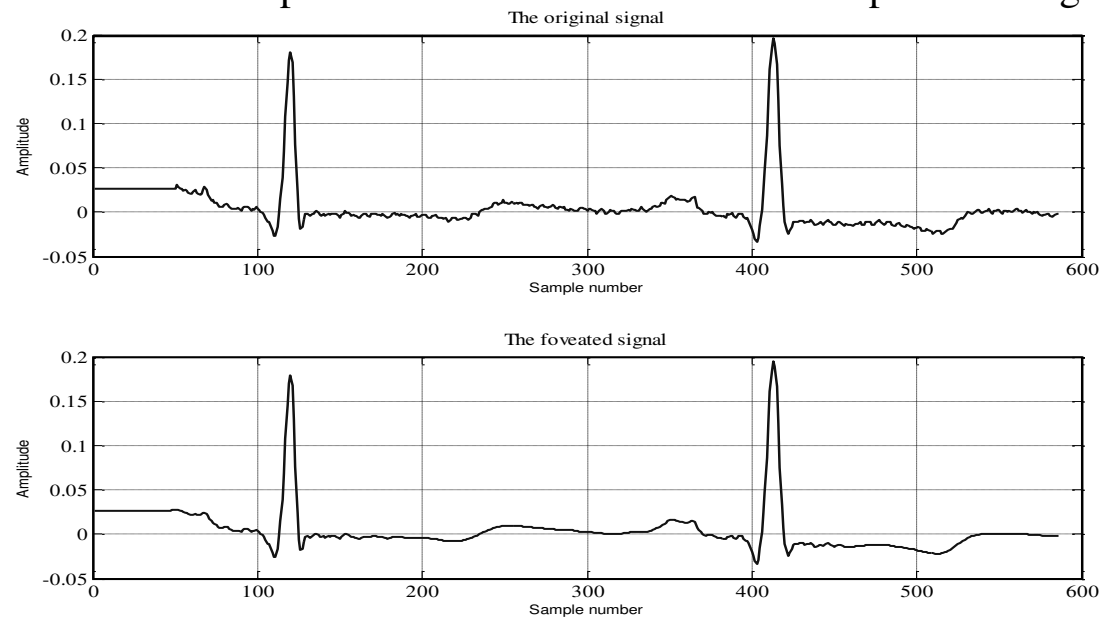

Fig. 6. The original and time domain foveation of the 1 'st beat of record 100 .

Journal of Engineering Sciences, Assiut University, Faculty of Engineering, Vol. 41, No. 6, November, 2013, E-mail address: jes@aun.edu.eg 
2218

Mohammed Abo-Zahhad et al., A new ECG compression algorithm based on wavelet foveation and Huffman coding techniques, pp. 2213 - 2230

\section{The Effect of Foveation on The Entropy of The ECG Signal}

To explore the effect of foveation on the ECG signal entropy the following example is considered. Consider random symbols levels of signal source $\mathrm{S}$ as $s_{1}, s_{2}, \ldots \ldots s_{N}$ and the self-information for each level $s_{i}$ as

$$
I\left(s_{i}\right)=\log \frac{1}{p_{i}}=-\log p_{i}
$$

where, $p_{i}$ denotes the probability of occurrence of level $s_{i}$. Entropy is the average selfinformation of all levels and is defined as:

$$
H(S)=\sum_{i} p_{i} \log _{2} \frac{1}{p_{i}}
$$

The entropy $H(S)$ of the mean normalized ECG signal is calculated considering the variation of $\alpha$, and $\beta$ parameters of the function $\omega(x)=\alpha|x-\gamma|+\beta$. Figures (7) and (8) show the effect of $\alpha$ and $\beta$ parameters on $H(S)$ and PRD of the foveated ECG signal. It is cleared from the two figures that $\alpha$ and $\beta$ have high effect on $H(S)$ and PRD of the foveated ECG signal.

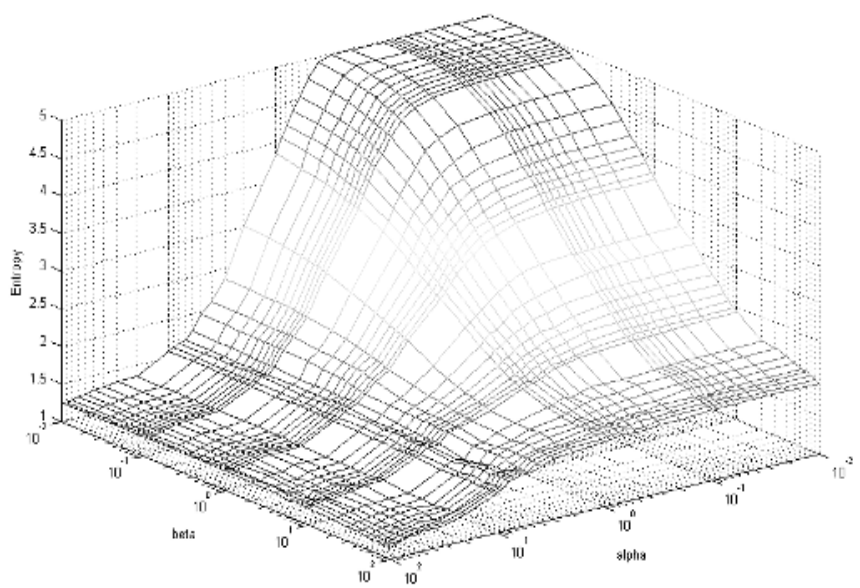

Fig. 7. The Entropy of the foveated signal versus $\alpha$ and $\beta$.

Journal of Engineering Sciences, Assiut University, Faculty of Engineering, Vol. 41, No. 6, November, 2013, E-mail address: jes@aun.edu.eg 


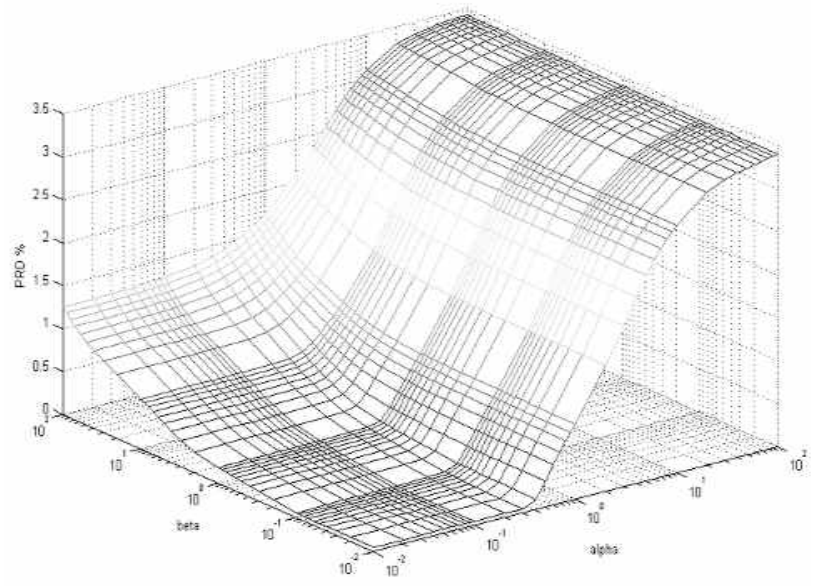

Fig. 8. The $\%$ PRD of the foveated signal versus $\alpha$ and $\beta$.

\section{Coding Algorithms}

Three coding methods, based on Huffman coding scheme, are adopted for coding the foveated ECG signal. These coding methods are optimal selective Huffman coding, adaptive Huffman coding and modified adaptive Huffman coding. Here, we present and analyze the performance of the listed coding methods. The performance of each method is measured based on the compression ratio $\mathrm{CR}$ and the compression time. The $\mathrm{CR}$ is calculated using the following equation.

$$
C R=\frac{\text { Length } \text { of } x(n) * 11}{\text { length of output stream }}
$$

where, $x(n)$ is the original signal sample and each sample is represented by 11 bits. The compression time is the time consumed in compressing the ECG signal. Considering practical applications, ECG compression algorithm should have an adequate compression rate and must be operated in real-time. So the compression time is considered here as a performance factor.

\subsection{Optimal selective Huffman coding}

Huffman code is the statistical code that provably provides the shortest average codeword length. It is closer than that of any other statistical code to the theoretical entropy bound. Thus, it offers the best compression performance. Moreover, Huffman code is prefix-free (i.e., no codeword is the prefix of another one) and, therefore, its decoding process is simple and easy to implement. The major problem that comes out when Huffman coding is used in compression is the large hardware overhead of the required decompressor. Specifically, the increase in the number of coded symbols causes an exponential increase in the number of code-words that should be decoded. For that reason, the approaches described in [18]-[19] and [21] encode only a few of the distinct symbols.

Journal of Engineering Sciences, Assiut University, Faculty of Engineering, Vol. 41, No. 6, November, 2013, E-mail address: jes@aun.edu.eg 
Mohammed Abo-Zahhad et al., A new ECG compression algorithm based on wavelet foveation and Huffman coding techniques, pp. 2213 - 2230

Specifically, among the k symbols $S_{1}, S_{2}, \ldots S_{k}$, only the m most frequently occurring ones, $s_{1}, S_{2}, \ldots . S_{m}(m<k)$, are Huffman encoded, while the rest, $S_{m+1}, S_{m+2}, \ldots . S_{k}$, remain uuencoded. Specifically, according to the optimal selective Huffman approach, $m+1$ Huffman code-words are used, $m$ for encoding the $m$ most frequently occurring symbols and 1 for indicating the unencoded symbols. The occurrence frequency of the latter codeword is equal to the sum of the occurrence frequencies of all the uuencoded symbols. An example of constructing Huffman codes and optimal Huffman codes are shown in Table (1) and Figure (9). Table (1) includes the compressed data, the frequency of occurrence of each of the possible symbols and the code-words of symbols based on Huffman coding and optimal Huffman coding. Figure (9) illustrates the full Huffman tree and the optimal selective Huffman tree.

\section{Table 1.}

Data, occurrence frequency, code-words and compressed data of Huffman coding and optimal selective Huffman coding

\begin{tabular}{|c|c|c|c|c|}
\hline \multirow[b]{2}{*}{ Data } & \multirow[b]{2}{*}{ symbols } & \multirow{2}{*}{$\begin{array}{l}\text { Occurrence } \\
\text { frequency }\end{array}$} & \multicolumn{2}{|c|}{ Code words } \\
\hline & & & $\begin{array}{c}\text { Huffman } \\
\text { codes }\end{array}$ & $\begin{array}{l}\text { Optimal selective } \\
\text { Huffman codes }\end{array}$ \\
\hline \multirow{5}{*}{ 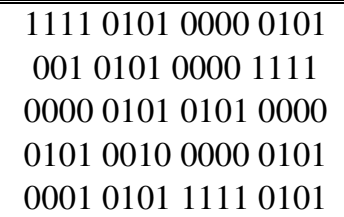 } & 0101 & $9 / 20$ & 1 & 1 \\
\hline & 0000 & $5 / 20$ & 01 & 01 \\
\hline & 1111 & $3 / 20$ & 001 & 001 \\
\hline & 0001 & $2 / 20$ & 0001 & 000001 \\
\hline & 0010 & $1 / 20$ & 0000 & 000010 \\
\hline $\begin{array}{l}\text { Compressed data using } \\
\text { Huffman coding }\end{array}$ & \multicolumn{4}{|c|}{ 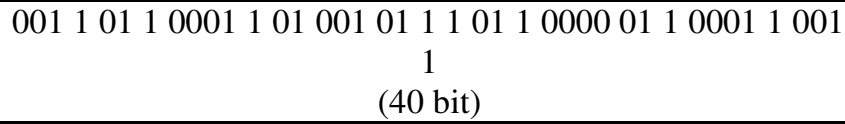 } \\
\hline $\begin{array}{l}\text { Compressed data using } \\
\text { optimal selective } \\
\text { Huffman coding }\end{array}$ & \multicolumn{4}{|c|}{$\begin{array}{c}001101100000011010010111011000010011 \\
00000110011 \text { (47 bit) }\end{array}$} \\
\hline
\end{tabular}

Journal of Engineering Sciences, Assiut University, Faculty of Engineering, Vol. 41, No. 6, November, 2013, E-mail address: jes@aun.edu.eg 


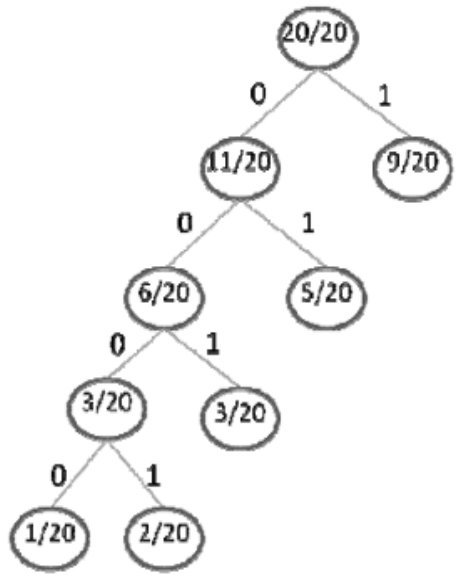

(a)

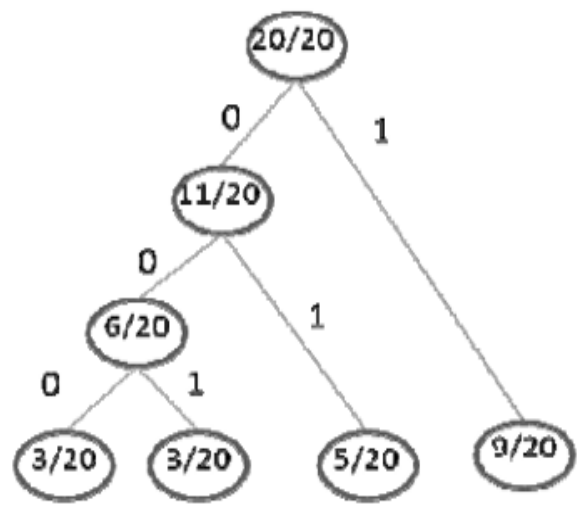

(b)

Fig. 9. (a) The full Huffman tree (b) the optimal selective Huffman tree

\subsection{Adaptive Huffman coding}

In this section a dynamic Huffman coding called adaptive Huffman coding technique has been introduced. It permits modifying the code as the symbols are being transmitted, with equal initial values of probabilities. This allows one-pass encoding and adaptation to changing conditions in data. The benefit of one-pass procedure is that the source can be encoded in real time, though it becomes more sensitive to transmission errors, since just a single loss ruins the whole code. For example, suppose we have 4 symbols a, b, c and d which occur as "abbbccdccc". Initially all the symbols will be having a frequency count of 1 and initial tree will be built as show in Figure (10-a), symbol 'a' will be encoded as 01 and its frequency count will be incremented to 2. The tree is updated as in Figure (10-b) and this time we will encode ' $b$ ' as 101 . This process continues until all the symbols are encoded. As the frequency count of a symbol increases, bits needed to encode the symbol decreases. So, in adaptive Huffman coding bits needed to encode a symbol increase or decrease dynamically and hence the name Dynamic Huffman Encoding arises. The codes for the 4 symbols a, b, c and d of the sequence "abbbccdccc" are

$\begin{array}{cccccccccc}\mathrm{a} & \mathrm{b} & \mathrm{b} & \mathrm{b} & \mathrm{c} & \mathrm{c} & \mathrm{d} & \mathrm{c} & \mathrm{c} & \mathrm{c} \\ 01 & 101 & 00 & 1 & 111 & 000 & 011 & 01 & 00 & 1\end{array}$

As a result, the final bit stream will be 0110100111100001101001 .

\section{Modified Huffman Encoding}

In some cases the number of symbols $\mathrm{S}$ is too much, that should be coded using 11bits for ECG signal or 8-bits for Alphabet messages. For coding such signal using adaptive Journal of Engineering Sciences, Assiut University, Faculty of Engineering, Vol. 41, No. 6, November, 2013, E-mail address: jes@aun.edu.eg 
Mohammed Abo-Zahhad et al., A new ECG compression algorithm based on wavelet foveation and Huffman coding techniques, pp. 2213 - 2230

Huffman coding, the initial code for each symbol will be 11-bits or 8-bits for ECG signal and Alphabet messages respectively. That means there is no reduction in bits required to code the signals. Add to that, the decrease in symbol code length is reduced slowly with the increase in a certain symbol occurrence because of the long initial code for symbols. Last challenge appears in using adaptive Huffman coding is that, in case a certain symbol appears lately, adaptive Huffman coding use a long code to represent that symbol longer than the initial code.

To overcome all these challenges a new and a qualified coding algorithm called Modified Huffman Coding is proposed in this work for compressing the ECG signal. In this technique the initial code for all symbols will be fixed whenever the symbol appears. Simply the Modified Huffman Coding system is explained in the flow chart shown in Figure (11). Here, a new symbol will be the first symbol appears in the transmitted symbols, called N_SYM which declare the appearance of a new symbol. This symbol code will send each time a new symbol appear, followed by a standard representation of the new appeared symbol (i.e. ASCII code for Alphabet messages or 11 bit PCM for ECG signal). Table (2) shows the sequence of symbol coding using the modified Huffman coding applied the sequence "abbbccdccc". The codes for the 4 symbols a, b, c and $d$ of the sequence "abbbccdecc" are

$\begin{array}{cccccccccc}\mathrm{a} & \mathrm{b} & \mathrm{b} & \mathrm{b} & \mathrm{c} & \mathrm{c} & \mathrm{d} & \mathrm{c} & \mathrm{c} & \mathrm{c} \\ 100 & 101 & 01 & 11 & 110 & 001 & 111 & 001 & 01 & 10\end{array}$

As a result, the final bit stream will be 1001010111110001111001001001 .

\section{Experiments and Results}

In this section, we study the performance of the presented three coding systems. The MIT-BIH normal Sinus Rhythm Database [22] was used to study the proposed coding systems. In our experiments a 10-min ECG recordings (record MIT100) which is a normal ECG record was applied in the coding experiments as a test signal. The sampling frequency is $360 \mathrm{~Hz}$ with resolution 12 bit per sample. In all experiments the signal is wavelet transformed using bior3.9 mother wavelet and the decomposition process is carried out up to the third level. The ECG, after wavelet foveation is coded using optimal selective Huffman coding, adaptive Huffman coding and modified adaptive Huffman coding.

The first experiment is adopted to explore the performance of the optimal selective Huffman coding. Figure (12) shows the first 2048 samples of record MIT100 compressed by optimal selective Huffman coding system. The figure contains the original ECG signal, reconstructed ECG signal and the error signal. The second experiment discusses the effect of number of the selected Huffman codeword optimal selective Huffman coding system over the compression rate and compression time. Table (3) illustrates the resulted CR, coding time and computational speed at different number of the selected Huffman code words. The computational speed is calculated using the following equation.

Comp. speed $=$ No. of coded samples $/$ Computation time

It is observed from the results stated in Table (3) that computation time is significantly increased with the increase in the number of the selected Huffman code words. Figure (13) shows the relation between the compression ratio, the compression time and the number of the selected Huffman code words.

Journal of Engineering Sciences, Assiut University, Faculty of Engineering, Vol. 41, No. 6, November, 2013, E-mail address: jes@aun.edu.eg 
Mohammed Abo-Zahhad et al., A new ECG compression algorithm based on wavelet foveation and Huffman coding techniques, pp. 2213 - 2230

Table 2.

The coding sequence using modified Huffman coding for the example of Figure (11).

\begin{tabular}{|c|c|c|c|c|c|c|c|c|c|c|}
\hline \multirow{3}{*}{ Stream } & \multicolumn{10}{|c|}{ Symbols } \\
\hline & \multicolumn{2}{|c|}{ New symbol } & \multicolumn{2}{|c|}{$\mathrm{a}$} & \multicolumn{2}{|c|}{$\mathrm{b}$} & \multicolumn{2}{|c|}{$\mathrm{C}$} & \multicolumn{2}{|c|}{$\mathrm{d}$} \\
\hline & Prob. & Code & Prob. & Code & Prob. & Code & Prob. & Code & Prob. & Code \\
\hline Standard & & & & "OO" & & "01" & & $" 10 "$ & & $" 11 "$ \\
\hline $\mathrm{a}$ & 1 & "1" & 1 & "0" & 0 & "" & 0 & "" & 0 & "'" \\
\hline $\mathrm{b}$ & 2 & "1" & 1 & "00" & 1 & "01" & 0 & "" & 0 & "" \\
\hline $\mathrm{b}$ & 2 & "0" & 1 & "10" & 2 & "11" & 0 & "" & 0 & "" \\
\hline $\mathrm{b}$ & 2 & "01" & 1 & "00" & 3 & "1" & 0 & "" & 0 & "" \\
\hline $\mathrm{c}$ & 3 & "1" & 1 & "000" & 3 & "01" & 1 & "001" & 0 & "" \\
\hline $\mathrm{c}$ & 3 & "1" & 1 & "000" & 3 & "01" & 2 & "001" & 0 & "'" \\
\hline $\mathrm{d}$ & 4 & "1" & 1 & "0101" & 3 & "00" & 2 & "001" & 1 & "0100" \\
\hline $\mathrm{c}$ & 4 & "11" & 1 & "001" & 3 & "10" & 3 & "01" & 1 & "000" \\
\hline $\mathrm{c}$ & 4 & "11" & 1 & "001" & 3 & "01" & 3 & "10" & 1 & "000" \\
\hline
\end{tabular}

Table 3.

The resulted CR, coding time and computational speed at different number of the selected Huffman code words.

\begin{tabular}{|c|c|c|c|}
\hline Number selected code words & coding time & Computational Speed & CR \\
\hline 4 & 4.9 & 897.4 & 4.32 \\
\hline 12 & 10.6 & 415.5 & 4.55 \\
\hline 20 & 21.8 & 201.2 & 4.71 \\
\hline 28 & 38.5 & 114.0 & 4.80 \\
\hline 36 & 61.0 & 71.9 & 4.89 \\
\hline 60 & 160.2 & 27.4 & 4.95 \\
\hline 100 & 436.0 & 10.1 & 4.99 \\
\hline 140 & 856.3 & 5.1 & 5.01 \\
\hline 180 & 1427.8 & 3.1 & 5.01 \\
\hline
\end{tabular}

The third experiment is to explore the performance of the adaptive Huffman coding system and the modified adaptive Huffman coding system. Figures (14) and (15) show the first 2048 samples of record MIT100 compressed by adaptive Huffman coding system. The figures contain the original ECG signal, reconstructed ECG signal and the error signal using the two coding systems respectively.

The fourth experiment is a comparative analysis between optimal selective Huffman coding algorithm, adaptive Huffman coding algorithm and modified adaptive Huffman coding algorithms with and without wavelet foveation, the results are shown in Table (4).

Journal of Engineering Sciences, Assiut University, Faculty of Engineering, Vol. 41, No. 6, November, 2013, E-mail address: jes@aun.edu.eg 
2224

Mohammed Abo-Zahhad et al., A new ECG compression algorithm based on wavelet foveation and Huffman coding techniques, pp. 2213 - 2230

The fifth experiment is a compression results using optimal selective Huffman coding algorithm, adaptive Huffman coding algorithm and modified adaptive Huffman coding algorithms based on optimal EPE thresholding, the results are shown in Table (5).

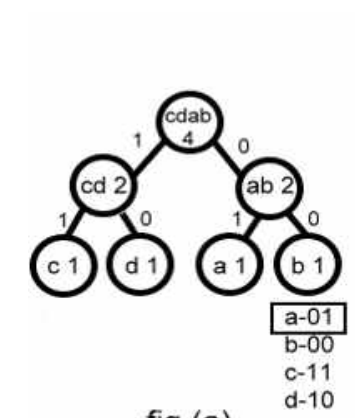

fig (a)

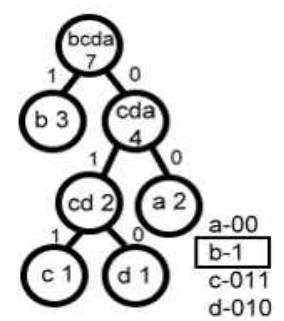

fig (d)

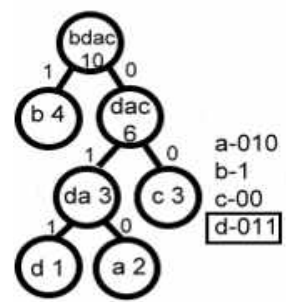

fig (g)

\section{Adaptive Huffman Encoding \\ For data pattern "abbbccdccc"}

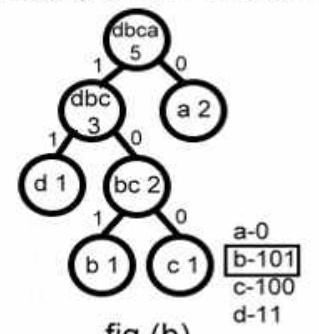

fig (b)

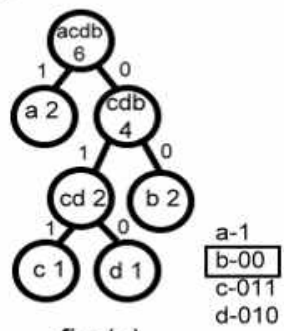

fig (c)

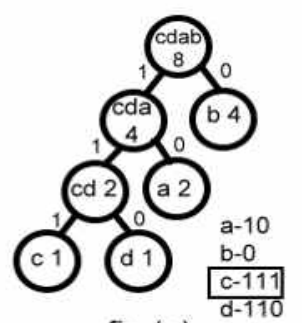

fig (e)

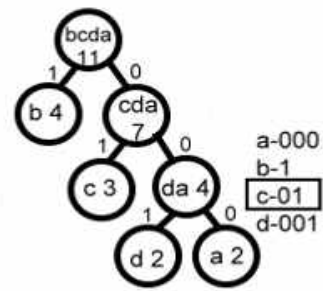

fig (h)

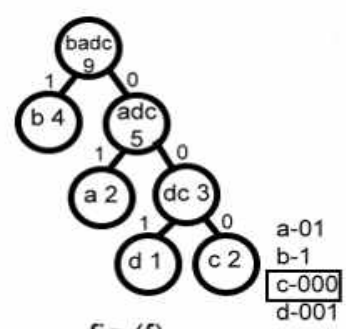

fig (f)

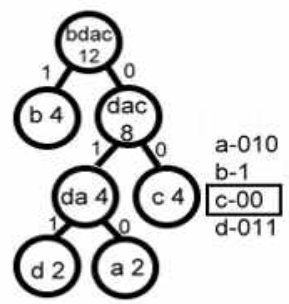

fig (i)

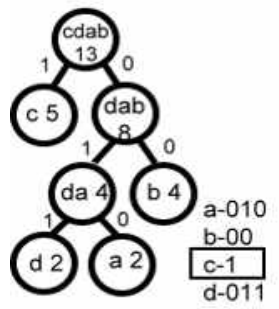

fig (j)

Encoded bit pattern :0110100111100001101001

Fig. 10. Adaptive Huffman coding system

Journal of Engineering Sciences, Assiut University, Faculty of Engineering, Vol. 41, No. 6, November, 2013, E-mail address: jes@aun.edu.eg 
Mohammed Abo-Zahhad et al., A new ECG compression algorithm based on wavelet foveation and Huffman coding techniques, pp. 2213 - 2230

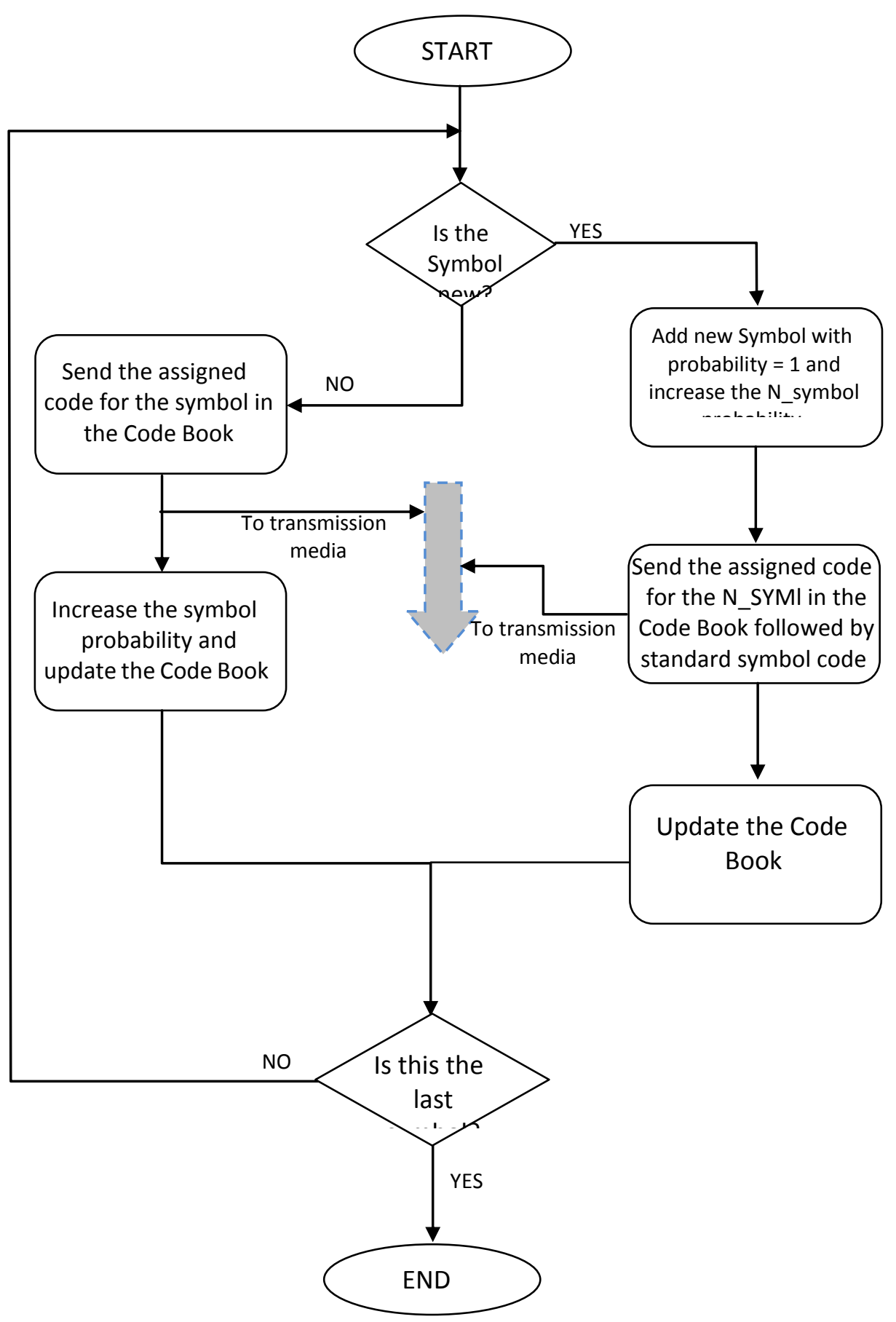

Fig. 11. Modified Huffman coding system flow chart.

Journal of Engineering Sciences, Assiut University, Faculty of Engineering, Vol. 41, No. 6, November, 2013, E-mail address: jes@aun.edu.eg 
Mohammed Abo-Zahhad et al., A new ECG compression algorithm based on wavelet foveation and Huffman coding techniques, pp. 2213 - 2230
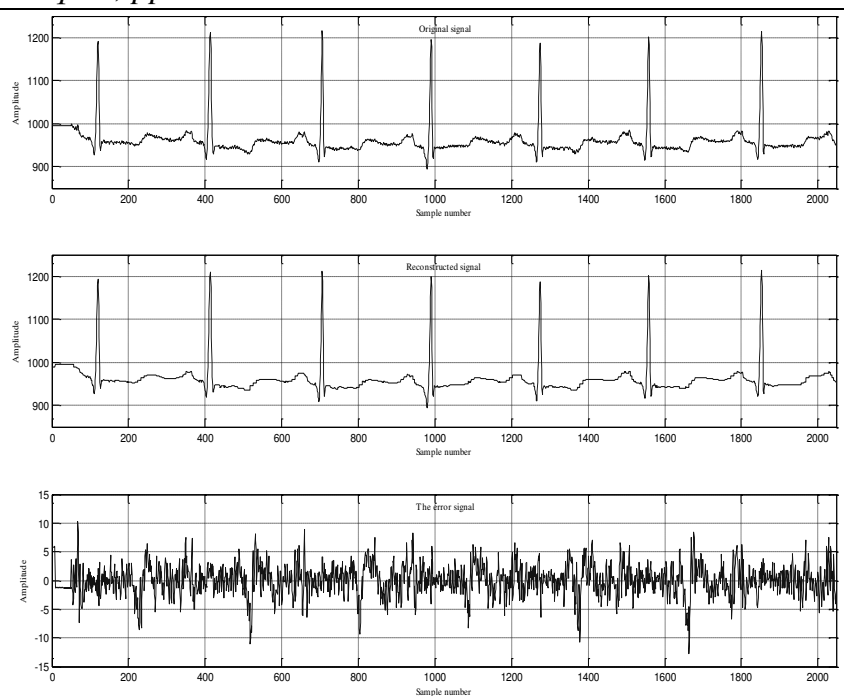

Fig. 12. Compression of Record 100 using optimal selective Huffman coding, a) Original signal. b) Reconstructed signal. c) Error signal.
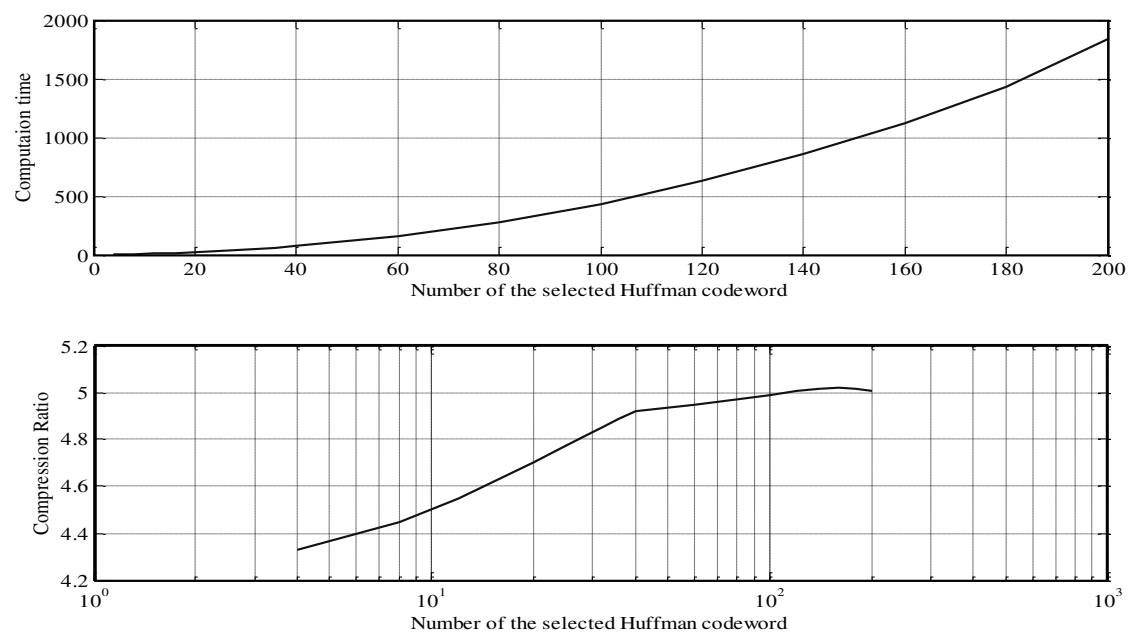

Fig. 13. performance of Compression using optimal selective Huffman coding. 
Mohammed Abo-Zahhad et al., A new ECG compression algorithm based on wavelet foveation and Huffman coding techniques, pp. 2213 - 2230
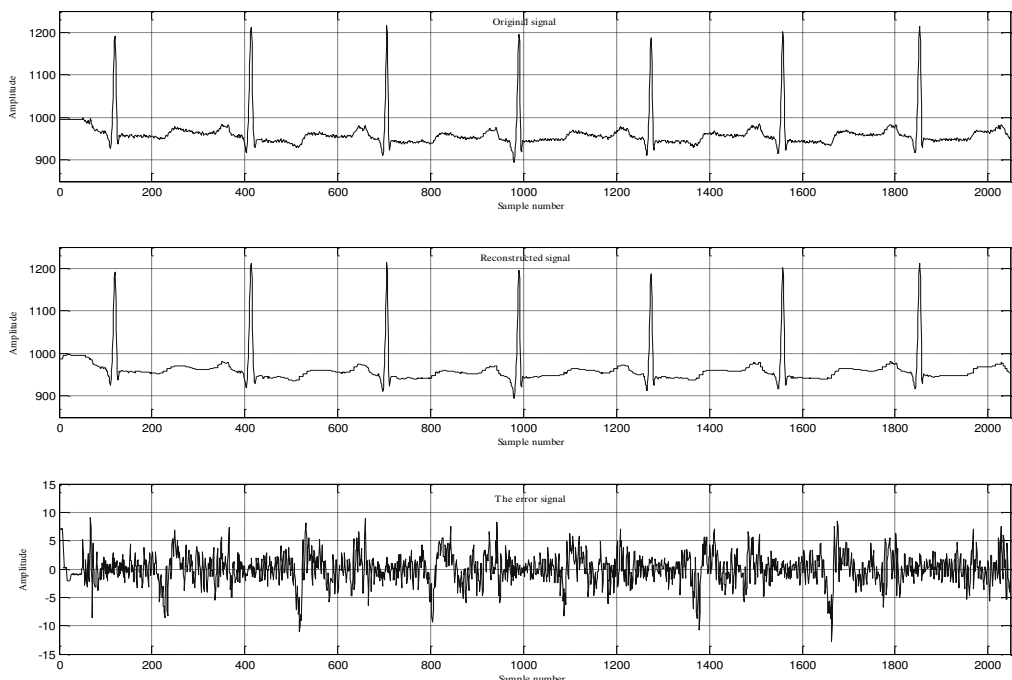

Fig. 14. Record 100 Compression using adaptive Huffman coding, a) Original signal. b) Reconstructed signal. c) Error signal.
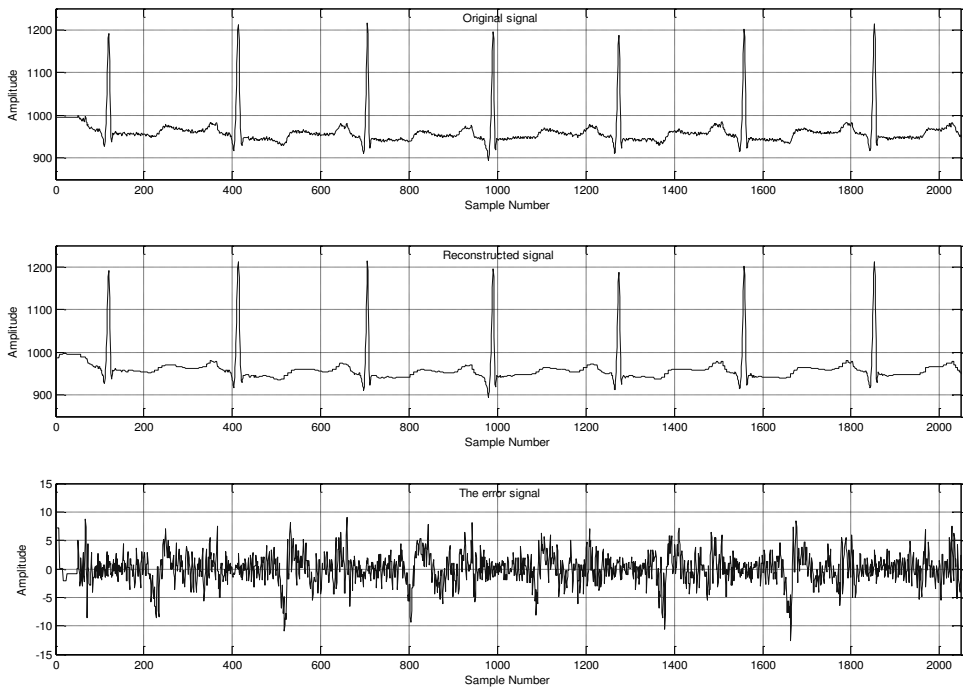

Fig. 15. Record 100 Compression using modified adaptive Huffman coding, a) Original signal. b) Reconstructed signal. c) Error signal. 
Mohammed Abo-Zahhad et al., A new ECG compression algorithm based on wavelet foveation and Huffman coding techniques, pp. 2213 - 2230

Table 4.

Comparison between the coding systems with foveation of record 100

\begin{tabular}{|c|c|c|c|c|c|}
\hline \multicolumn{2}{|c|}{} & CR & PRD & PSNR & $\begin{array}{c}\text { Comp. Speed } \\
\text { (Sample/ sec.) }\end{array}$ \\
\hline \multirow{4}{*}{$\begin{array}{c}\text { With } \\
\text { Foveation }\end{array}$} & OHSC & 4.99 & 0.273 & 53.3 & 146 \\
\cline { 2 - 6 } & AHC & 5.25 & 0.266 & 53.5 & 1.2833 \\
\cline { 2 - 6 } & MAHC & 4.84 & 0.266 & 53.5 & 3.8437 \\
\hline \multirow{4}{*}{$\begin{array}{c}\text { Without } \\
\text { Foveation }\end{array}$} & OHSC & 3.42 & 0.114 & 60.8 & 430 \\
\cline { 2 - 6 } & AHC & 3.58 & 0.076 & 64.4 & 4.2 \\
\cline { 2 - 6 } & MAHC & 3.36 & 0.079 & 64.1 & 16.2 \\
\hline
\end{tabular}

\section{Table 5.}

The coding systems based on optimal EPE thresholding for record MIT100

\begin{tabular}{|c|c|c|c|c|}
\hline \multicolumn{2}{|c|}{} & CR & PRD & PSNR \\
\hline \multirow{2}{*}{$\begin{array}{c}\text { Foveation and } \\
\text { optimal EPE } \\
\text { thresholding }\end{array}$} & OHSC & 7.66 & 0.482 & 48.4 \\
\cline { 2 - 5 } & AHC & 8 & 0.502 & 48 \\
\cline { 2 - 5 } & MAHC & 6.87 & 0.699 & 45.1 \\
\hline
\end{tabular}

\section{Conclusions}

In this paper a three coding systems for compressing ECG signals based on wavelet foveation principle. The idea of utilizing the foveation principle is the reduction in the amount of data contained in the foveated ECG signal. There are many advantages of the proposed approach, such as the approximation error (resulted from foveation mask) is spread non-uniformly along the beat waveform, exhibiting lower values around critical clinical importance points. The experiments show that the modified adaptive Huffman coding which is proposed in this paper achieved the best performance over the other coding systems. The work presented, in this paper may be helpful for designing efficient ECG compressor. A future work of this paper, the foveation operator may be realized using lookup tables which can be simplified by binary approximations, thus greatly smooth the implementation method.

\section{References}

[1]M. Abo-Zahhad, "ECG Signal Compression Using Discrete Wavelet Transform" book chapter, pp. 143-168, 2011. (Chapter 8 of Discrete Wavelet Transforms - Theory and Applications, ISBN: 978-953-307-185-5, published by InTech )

[2] S. D. Stearns, L.-Z. Tan, and N. Magotra, " Lossless compression of waveform data for efficient storage and transmission, "IEEE Transactions on Geoscience and Remote Sensing, vol. 31, no. 3, pp. 645-654, 1993.

Journal of Engineering Sciences, Assiut University, Faculty of Engineering, Vol. 41, No. 6, November, 2013, E-mail address: jes@aun.edu.eg 
Mohammed Abo-Zahhad et al., A new ECG compression algorithm based on wavelet foveation and Huffman coding techniques, pp. 2213 - 2230

[3]R. Loges waran and C. Eswaran, "Performance survey of several lossless compression algorithms for telemetry applications," International Journal of Computers and Applications, vol. 23, no. 1, pp. 1-9, 2001.

[4]K. Sayood, Introduction to Data Compression ,Morgan Kaufmann, San Francisco, Calif, USA, 3rd edition, 2006.

[5] M. C. Aydin, A. E. Cetin, and H. Koymen, "ECG data compression by subband coding ," Electronics Letters, vol. 27, no. 4, pp.359-360, 1991.

[6] S. C. Tai, "Six band subband coder on ECG waveforms,"Medical \& Biological Engineering \& Computing, vol.30, no.2, pp. 187-192, 1992.

[7]B. A. Rajoub, "An efficient coding algorithm for the compression of ECG signals using the wavelet transform," IEEE Transactions on Biomedical Engineering , vol. 49, no. 4, pp. 355362, 2002.

[8] M. Velasco, F. Roldn, J. Llorente and Kenneth E. Barner,"Wavelet Packets Feasibility Study for the Design of an ECG Compressor," IEEE Trans. on Biomed. Eng., vol. 54, no. 4, pp 766-769, Apr. 2007.

[9]R. Benzid, F. Marir, A. Boussaad, M. Benyoucef and D. Arar,'Fixed percentage of wavelet coefficients to be zeroed for ECG compression," Electronic Letters, vol. 39, no. 11, pp. 830831, May 2003.

[10] Pooyan, M., Taheri, A., Goudarzi, M. M., and Saboori, I., "Wavelet compression of ECG signals using SPIHT algorithm," Transactions on Engineering, Computing and Technology, vol. 2, 2004.

[11] S. Miaou, H. Yen, and C. Lin, "Wavelet-based ECG compression using dynamic vector quantization with tree code vectors in single codebook," IEEE Trans. on Biomedical Eng., vol. 49, no. 7, pp. 671680, Jul. 2002.

[12] Sarada Prasad Dakua and Jyotinder Singh Sahambi, "Lossless ECG Compression for Event Recorder Based on Burrows-Wheeler Transformation and Move-To-Front Coder ", International Journal of Recent Trends in Engineering, vol. 1, no. 3, May 2009.

[13] R. Kannan and C. Eswaran," Lossless Compression Schemes for ECG Signals Using Neural Network Predictors", EURASIP Journal on Advances in Signal Processing, 2007.

[14] Z. Arnavut, Lossless and Near-Lossless Compression of ECG Signals with Block-Sorting Techniques, The International Journal of High Performance Computing Applications, vol. 21, no. 1, pp. 50-58, 2007.

[15] C. D. Giurcaneanu, I. Tabus, and S. Mereuta, "Using contexts and R- R interval estimation in lossless ECG compression," Computer Methods and Programs in Biomedicine , vol. 67, no. 3, pp. 177-186, 2002.

[16] E.C. Chang, S. Mallat, C. Yap, "Wavelet foveation", J. Appl. Comput. Harmonic Analysis 9, pp. 312-335, 2000.

[17] Iulian B. Ciocoiu, "ECG Signal Compression Using 2D Wavelet Foveation", International Journal of advanced science and technology, vol. 13, 2009.

[18] G.C. Chang and Y.D. Lin," An Efficient Lossless ECG Compression Method Using Delta Coding and Optimal Selective Huffman Coding ", IFMBE Proceedings, pp. 1327-1330, 2010.

[19] Kavousianos X, Kalligeros E, Nikolos D, “Optimal Selective Huffman Coding for TestData Compression,” IEEE Trans. on Computers, vol. 56, pp. 1146-1152, 2007.

[20] Huffman D. A., "A Method for the Construction of Minimum Redundancy Codes," Proceedings of the Inst. Radio Engineers, vol. 40, pp. 1098-1101, 1952.

Journal of Engineering Sciences, Assiut University, Faculty of Engineering, Vol. 41, No. 6, November, 2013,E-mail address: jes@aun.edu.eg 
Mohammed Abo-Zahhad et al., A new ECG compression algorithm based on wavelet foveation and Huffman coding techniques, pp. 2213 - 2230

[21] A. Jas, J. Ghosh Dastidar, M.-E. Ng, and N .A. Touba, "An Efficient Test Vector Compression Scheme Using Selective Huffman Coding," IEEE Trans. Computer Aided Design, vol. 22, pp. 797-80 6, June 2003.

[22] L. Glass J. M. Hausdorff P. C. Ivanov R. G. Mark J. E.Mietus G. B. Moody C.-K. Peng A. L. Goldberger, L.A. N. Amaral and H. E. Stanley, "Physiobank, physiotoolkit, and physionet: Components of a new researcher source for complex physiologic signals," Circulation, vol. 101, no. 23, pp. 215-220, June 2000.

\section{خوارزمية جديدة لضغط إشارة رسم القلب الكهربائية مبنية

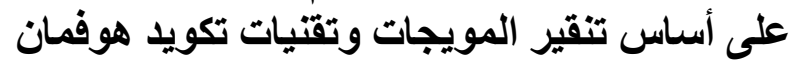 أ. د. محمد أبوزهاد أبوزيد - أ. د. صباح محمد أحمد - م. أحمد زكريا

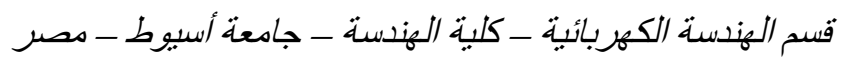

الملخص العربى

يعرض هذه البحث خوارزمية جديدة لضغط إثـارة رسم القلب الكهربائية مبنية على أساس تنقير المويجات

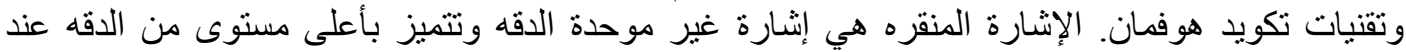

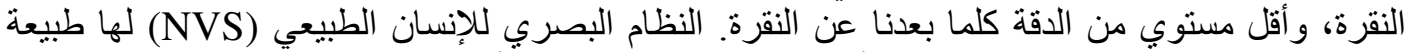

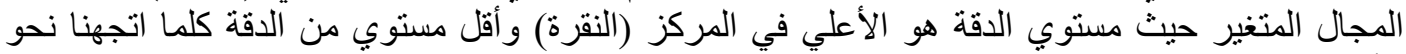

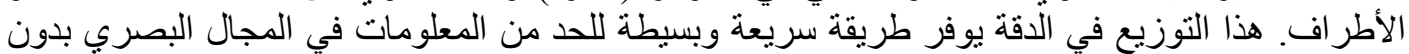

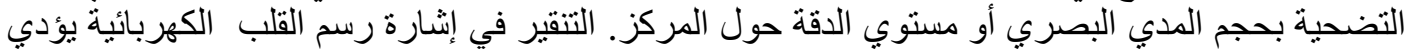

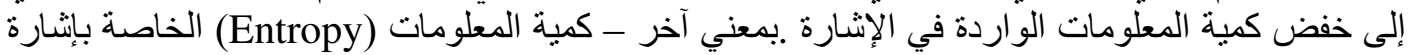
رسم القلب الكهربائية المنقره سوف تقل وبالألتالي سوف يزيد من نسبة الضغط. تلكود الاشارة بعد التنقير بالإنتقاء الأمثل لتكويد هوفمان (Optimal Selective Huffman Coding) وتكويد هوفمان المتكيف (Modified Adaptive Huffman وتكويد هوفمان المتكيف المعدل (Adaptive Huffman Coding)

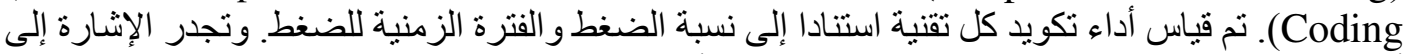

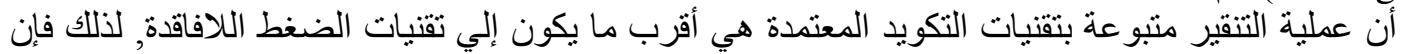

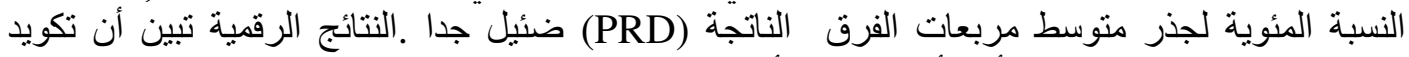
هو فمان المتكيف المعدل يعطي أداء أفضل برئ الفين الأنظمة الثنلاثنة للتكويد.

كلمات البحث : تتقير المويجات, الإنتقاء الأمثل لتكويد هوفمان, تكويد هوفمان المتكيف, تكويد هوفمان المتكيف المعدل , تقنيات الضغط اللافاقدة.

Journal of Engineering Sciences, Assiut University, Faculty of Engineering, Vol. 41, No. 6, November, 2013, E-mail address: jes@aun.edu.eg 